\title{
SER NEGRO NO MARAJÓ: NOTAS SOBRE IDENTIDADE E RACISMO NA AMAZÔNIA PARAENSE
}

\section{BEING BLACK IN MARAJÓ: NOTES ON RACIAL IDENTITY AND RACISM IN THE AMAZON}

\author{
Jacqueline Tatiane da Silva Guimarães \\ Faculdade de Serviço Social do Campus \\ Universitário do Marajó/Breves -FACSS/UFPA
}

\section{RESUMO}

Abordamos sobre ser negro e o racismo no Marajó, a fim de refletir sobre as suas particularidades na região. Primeiramente, tratamos sobre a história do negro na Amazônia, problematizando a sua presença na cultura da Amazônia paraense. Posteriormente, discorremos sobre o processo de lutas e resistências que consolidaram as políticas afirmativas e os impactos do colorismo nos processos da autodeclaração e por consequência na identidade racial. Por fim, apresentamos os resultados da pesquisa, que teve como lócus o município de Breves (Marajó/PA). Esta pesquisa é exploratória, pautada em levantamento bibliográfico e entrevista estruturada realizada com 34 sujeitos, sendo 32 discentes e dois técnicos de instituições de ensino superior. A pesquisa foi realizada nos meses de agosto e setembro de 2017. Verificamos que os debates sobre raça, etnia, racismo, negro e negritude ainda se constituem em verdadeiros pontos de interrogação para os discentes dos cursos de nível superior, quadro que indica as fragilidades na educação básica destes sujeitos e sendo uma problemática que acaba por não ser superada pelos projetos pedagógicos dos cursos que ainda não conseguiram consolidar uma educação antirracista.

Palavras-chave: Marajó. Ser negro. Direitos Humanos.

\section{ABSTRACT}

We approached being black and racism in Marajó, in order to reflect about its peculiarities in the region. First, we deal with the history of blacks in the Amazon, questioning their presence in the culture of the Amazon from Pará. Subsequently, we discussed the process of struggles and resistance that consolidated affirmative policies and the impacts of colorism on the processes of self-declaration and consequently racial identity. Finally, we present the results of the research, whose locus was the municipality of Breves (Marajó / PA). This research is exploratory, based on bibliographic survey and interview structured study carried out with 34 subjects, 32 students and 2 technicians from higher education institutions. The research was carried out in August and September 2017.We note that debates about race, ethnicity, racism, black and blackness 
are still real question marks for students of higher education courses, a table that indicates the weaknesses in the basic education of these subjects and being a problem that ends up not being surpassed by the pedagogical projects of the courses that have not yet managed consolidate anti-racist education.

Key-words: Marajó. Being Black. human rights. 


\section{I - INTRODUÇÃO}

O presente artigo é resultado de estudos desenvolvidos em grupo de pesquisa que visa refletir e dar visibilidades aos temas dos direitos humanos da infância e da juventude no Arquipélago do Marajó, tendo como especial enfoque o debate da diversidade étnico-racial, portanto, problematizando o racismo e o ser negro na Amazônia marajoara. Pensar em "Ser negro no Marajó" vem de um processo de observação e problematização tomando a questão do negro na Amazônia, e especificamente no Marajó, a fim de romper com a ausência de debates concretos sobre o racismo na região. Partindo das seguintes questões que nos guiam: 1) como se dá o racismo na Amazônia marajoara? 2) Quais os seus desdobramentos, considerando as particularidades da região?

Primeiramente abordamos sobre a história do negro na Amazônia, problematizando a sua presença na cultura paraense e ausência na literatura nacional ao tratar sobre a presença do africano na região amazônica. Posteriormente, discorremos sobre o processo de lutas e resistências que consolidaram as políticas afirmativas, salientando as Leis $\mathrm{n}^{\circ}$ 10.639 e 11.645/o8 (que se complementam), bem como o Estatuto da Igualdade Racial (Lei $\mathrm{n}^{\circ} 12.288$ de julho de 2010), assim como os impactos do colorismo nos processos da autodeclaração e por consequência na construção de uma identidade racial.

Por fim, realizamos considerações sobre as particularidades da região marajoara, tal como a sua história e o quadro social e econômico, destacando a sua extensão e diversidade territorial, a fim de localizar e caracterizar o município de Breves. Esta pesquisa é de caráter exploratório, pautada em levantamento bibliográfico e entrevista estruturada realizada com 34 sujeitos, sendo 32 discentes e dois técnicos de instituições de ensino superior do município de Breves (Marajó/PA). Destacamos que a pesquisa foi realizada no período de agosto a setembro de 2017, em que foram assinados termos de consentimento e para a garantia do sigilo quanto a identidade dos entrevistados utilizamos iniciais de nomes e sobrenomes fictícios. 
Verificamos que os debates sobre raça, etnia, racismo, negro e negritude ainda se constituem em verdadeiros pontos de interrogação para os discentes dos cursos de nível superior do município de Breves, quadro que indica as fragilidades na educação básica destes sujeitos, inclusive, sendo uma problemática que acaba não sendo superada pelos projetos pedagógicos dos cursos de bacharelado e de licenciatura que ainda não vão para o enfrentamento, numa perspectiva de uma educação antirracista.

\section{II - O NEGRO NA AMAZÔNIA}

Infelizmente, o percurso do negro africano na região amazônica não destoou da trajetória de exploração que se tornaram comuns em outras regiões do país ${ }^{1}$. Entretanto teve particularidades que devem ser destacadas. Particularidades estas que devem ser a base para pensarmos sobre o racismo e o ser negro na Amazônia, que pressupõe uma compreensão sobre a inserção e atuação do negro numa região que historicamente convencionou-se que a principal mão de obra escrava foi somente a indígena.

Historiadores, como o paraense Vicente Salles, na década de 1970, em sua obra "O negro no Pará", foi um dos poucos que problematizou sobre a presença destes sujeitos em uma região que se acreditava que somente a mão de obra indígena foi escravizada, dando centralidade ao estado do Pará. Indo de encontro com o que a literatura nacional expunha. Isto pode ser constatado nos escritos de Priore e Venâncio (2010, p. 68).

$\mathrm{Na}$ Amazônia, nem o negro africano e nem o indígena foram descartados enquanto mão de obra escrava, tendo sido ambos livremente explorados. Todavia, se observa um silenciamento quanto à presença do negro nessa região. A presença do negro na Amazônia é registrada comumente por pesquisadores amazônidas que inquietos com tal ausência passam a se debruçar e perquirir os caminhos trilhados pelos negros africanos e influências exercidas por estes na constituição do que hoje compreendemos ser uma

\footnotetext{
${ }^{1}$ Quanto a trajetória do negro no Brasil, indicamos Albuquerque e Fraga Filho (2006) e Priore e Venâncio (2010).
} 
cultura própria da Amazônia, percebendo a sua presença na dança, na culinária, nos sotaques e na religião. Quanto a isto, José Maia Bezerra Neto $(2008,167)$, salienta que:

\begin{abstract}
Ainda hoje causa certo espanto, até mesmo entre o público acadêmico, a afirmação da importância em seus vários sentidos da escravidão negra de origem africana, portanto da presença negra, na Amazônia como um todo, inclusive no Pará. Isto porque, considerada há muito tão-somente terra de índios e florestas, tornou-se a (história da) região amazônica refém de modelos historiográficos ou interpretativos de sua história construídos desde pelo menos a segunda metade do século XIX. Modelos explicativos em que sobressaía em larga medida a tese comum de que a região em sua condição periférica, baseada sócioeconomicamente no extrativismo, não desenvolveu plantations; portanto, a escravidão negra, embora presente, fora de pouca ou nenhuma importância, inclusive demograficamente.
\end{abstract}

Bezerra Neto (2008, p. 168) prossegue afirmando que enquanto uma consequência de um resultado acumulativo de estudos de historiadores e cientista sociais que vieram se desenvolvendo, hoje há uma compreensão de que a escravidão negra no Brasil foi para além da plantation, ou seja, não estaria voltada tão somente para economia agroexportadora da monocultura, mas também se fizeram presentes no extrativismo, atividade que predominou na Amazônia.

A Amazônia se constitui em um território extenso e heterogêneo, envolvido pela diversidade em todos os seus níveis, seja ao que se refere à fauna e à flora, quanto em características geográficas que também incidem diretamente nos modos de vida, na cultura e na história de suas populações que também é extremamente diversa. No presente estudo não há o entendimento de que a história do negro no território brasileiro se deu de modo homogeneizado, mas sim se pretende dar visibilidade à necessária busca de registrarmos as diversas histórias destes sujeitos.

Ao tratarmos sobre esta história que necessita ser adensada na Amazônia, temos como recorte a região do Marajó, que segundo Sarraf-Pacheco (2012, p. 2) foi o primeiro território amazônico a ter a presença africana. Os espaços marajoaras teriam sido propícios para a cultura bovina, tendo as suas primeiras cabeças de gado, chegado provavelmente, em 1644 e ficado ao encargo "dos primeiros filhos das Áfricas”, (SARRAFPACHECO, 2012, p. 2). 
Conforme Peres e Azevedo (2015, p. 8), o processo histórico de inserção da mão de obra africana na Amazônia se deu a partir de iniciativas incentivadas pela Igreja Católica que se posicionava contra a escravização dos indígenas na Colônia e intencionavam a sua catequização, deste modo, tomando para si a defesa da liberdade dos povos originários. Entretanto, se fazia necessário garantir mão de obra para o cultivo da terra.

Neste sentido, houve a substituição da mão de obra indígena pela mão de obra negra africana, em que a presença negra na Amazônia se tornou mais intensa a partir de 1755 com a criação da Companhia Geral do Comércio do Grão-Pará e Maranhão, correspondendo ao período pombalino, sendo estimulada a produção agrícola na região. Como muito bem já destacado por Salles (1971, p. 67), o regime escravista não distinguia os grupos étnicos que dominava, quando se referia aos não brancos europeus.

A inserção do negro africano na Amazônia corresponde à diversidade não somente étnico-racial, mas significa, sobretudo, a diversidade cultural e religiosa que é vivida e experimentada pelo amazônida, que aliado às resistências e combates travados pelos indígenas, representa o que Vicente Salles (2015) se refere como "Africanização da pajelança". Portanto,

Não se pode considerar desprezível a contribuição cultural africana na Amazônia. Essa contribuição se manifesta nos folguedos populares, na culinária, no vocabulário, enfim nos vários aspectos do folclore regional. Todavia não se pode testemunhar a sobrevivência de um culto puramente africano, pelo menos no Pará, onde a incorporação de elementos católicos dos chamados 'encantados' indígenas gerou um batuque extremamente sincretizado, modernizado com influência do candomblé baiano e da umbanda do Rio de Janeiro. (SALLES, 2015; p. 26).

As heranças do povo negro africano na Amazônia foram várias, dentre as quais novamente destacamos o seu principal símbolo de resistência, que são os quilombos, que até hoje persistem e resistem. Segundo dados da Fundação Cultural Palmares, ainda em 2014, das 2 mil comunidades quilombolas certificadas, identificou-se a existência de 406 comunidades quilombolas em estados como o Amapá, Amazonas, Maranhão e Pará² .

\footnotetext{
${ }^{2}$ Atualmente, existem 3.386 comunidades quilombolas reconhecidas distribuídas pelo território brasileiro, indo do Sul a Amazônia, o que segundo a CONAQ (Coordenação Nacional de Articulação das Comunidades
} 
Discorrer sobre estes processos históricos da inserção do negro na Amazônia visa justamente nos reportar sobre as particularidades e complexidade do racismo numa região com fortes influências da cultura indígena e africana (não havendo uma população em sua maioria branca, como em outras regiões do país) e que vivem e resistem para além dos territórios dos quilombos.

\section{III - ENTRE RECONHECIMENTO DA LUTA E RESISTÊNCIAS}

João Batista de Lacerda, em 1911 no Congresso Universal de Raças em Paris, decretava que com a vinda dos europeus para o Brasil (que se deu com intensa organização a fim de facilitar a vinda destes) dentro de 100 anos não haveria mais negros no país, sobrevivendo assim a "raça mais apta, forte e inteligente" (STEPAN, 2055; p. 166). Tal resultado se daria a partir de forte empenho em prol de políticas eugenistas que visavam embranquecer a população brasileira3 .

Entretanto, é necessário destacar que a população negra, assim como os demais grupos sociais excluídos, não foi passiva às diferentes estratégias de controle e subalternização. Aliás, até hoje a população negra existe, resiste e persiste. A história do negro no Brasil foi uma história que se fez e faz a partir da resistência.

Verifica-se ao longo do século XX, o protagonismo do movimento social negro que ao se contrapor e fazer uma frente de resistência à ideologia do branqueamento e do mito da democracia racial passa também a reivindicar por políticas públicas preferenciais junto ao Estado (MARÇAL, 2011, p. 12).

Na década de 1990, houve iniciativas tímidas por parte do governo e empresas multinacionais a fim de darem prosseguimento às ações afirmativas. Contudo, como bem

Negras Rurais Quilombola) pode ultrapassar o número de 5 mil futuramente. Mais informações nos Portais $<$ http://conaq.org.br/> e <https://cpisp.org.br/>.

${ }^{3}$ Sobre as medidas das políticas eugenistas na América Latina, indicamos a primorosa obra "A hora da Eugenia" de Nancy Stepan (2005), que aborda sobre as diferentes iniciativas planejadas e operadas pelos países da América Latina em torno de políticas eugenistas que visavam pôr países como o Brasil num processo de branqueamento que significaria civilização e progresso. 
salienta Marçal (2011, p. 71), a década de 2000 foi importante momento histórico para militantes e intelectuais negros, em que pela primeira vez surgem políticas preferenciais com o objetivo de favorecer o contingente populacional negro com as chamadas Políticas de Ação Afirmativas (PAA). As PAA são iniciativas estritamente estatais, assim como as políticas de cotas nas universidades federais.

Em torno do processo de democratização e fortalecimento dos princípios dos Direitos Humanos, observa-se um movimento de caráter mundial, fortalecido pela sociedade civil e movimentos sociais que passaram a reivindicar por políticas de reparação, algo que Abreu, Mattos e Dantas (2010, p. 22), se referem como dever de memória.

Quando nos referimos ao dever de memória é importante indicar que as históricas desigualdades raciais não têm como serem esquecidas, pois diariamente elas se apresentam no nosso cotidiano, como podemos observar em pesquisas e estudos recentemente divulgados. Conforme dados do Instituto Brasileiro de Geografia e Estatística (IBGE), de fevereiro de 2017, os trabalhadores pretos e pardos são os mais atingidos pelo desemprego, correspondendo a $64 \%$ de um total de 12,3 milhões. Entre a média nacional de desemprego que é de $12 \%$, entre brancos é 9,5\%, sendo que entre negros a média é de $14,4 \%$ e 14,1\% entre os pardos4.

Quando aliado o debate da diversidade étnico-racial à perspectiva de gênero observamos também o quanto mulheres negras são cotidianamente atravessadas por diferentes tipos de violações de direitos humanos. Em artigo publicado pelo Portal Geledés 5 , pautado em dados expostos no Mapa da Violência, nos anos entre 2003 e 2013,

4 Pretos e pardos sofrem mais com o desemprego. Disponível em: $<\underline{\text { http://www.redebrasilatual.com.br/cidadania/2017/03/pretos-e-pardos-sofrem-mais-com-desemprego-aponta-ibge }>\text {; }}$ acesso: $10 / 12 / 2017$.

5

Mortes de mulheres negras aumentam 54\% em dez anos .Disponível em $<$ https://www.geledes.org.br/mortesde-mulheres-negras-aumentam-54-em-dez-anos/>; acesso: 12/02/2018. 
houve uma diminuição da violência praticada contra mulheres brancas, correspondendo a 10\%, enquanto que entre as mulheres negras aumentou $54 \%$ em todo país.

Enquanto isso no Pará, 82,39\% das pessoas abaixo da linha da pobreza são pretas ou pardas, segundo o "Mapa da Exclusão Social do Pará 2016”. Destas considerações é importante compreender que no nosso país, a pobreza tem cor. Ou seja, o racismo se constitui em um marco produtor e mantenedor da histórica desigualdade social no país. Os dados apresentados acima representam a forte tensão racial que persiste no Brasil.

Diante de uma sociedade que oferece uma democracia racial ilusória, no qual as práticas de violências são mascaradas por uma falsa cordialidade legitimada por instituições que propagam o racismo, se faz fundamental destacar o papel estratégico que a Universidade, enquanto lugar de construção do conhecimento, passa a assumir num momento de efervescência política à medida que "todos" se voltam para a construção de uma sociedade democrática e igualitária, sobretudo após a Constituição Federal de 1988.

Todavia, iniciativas concretas se deram a partir da III Conferência da ONU contra o Racismo, a Discriminação, a Xenofobia e Intolerâncias Correlatas, ocorrida em setembro de 2001, na cidade Durban, África do Sul (MARÇAL, 2011; p. 11). E em 2002 foi lançado o Programa Diversidade na Universidade, uma parceria do Ministério da Educação, financiado pelo Banco Interamericano de Desenvolvimento (BID), sendo também um resultado da Conferência de Durban, que visava justamente refletir sobre potenciais estratégias para uma política de ações afirmativas para o combate ao racismo ${ }^{6}$.

É possível constatar que as Políticas de Ação Afirmativas (PAA) partem da perspectiva do dever de memória, que se destina a pensar ações e estratégias que visem garantir:

[...] por parte do Estado e da sociedade, de que determinados acontecimentos não serão esquecidos, que continuarão lembrados na memória de grupos e nações registradas na história do país. Mais ainda, que grupos detentores de memórias de sofrimento podem e devem ter reconhecidos sua história, memória e patrimônio (ABREU, 2012; p. 107).

\footnotetext{
${ }^{6}$ Ibidem, p. 76.
} 
Deste modo, passa a se constituir dever do Estado, por meio de suas instituições e políticas públicas, garantir ações que tenham por objetivo perpetuar os conhecimentos, saberes, história e cultura de grupos étnicos e raciais que foram duramente oprimidos ao longo da constituição social e histórica deste país.

Apesar do movimento recente ainda consolidado por um programa que foi encerrado em 2007, cabe à universidade garantir, o que aqui nos referimos como um direito de memória que deve ser garantido à população negra, pois apesar de algumas conquistas, os desafios ainda são muitos, dentre eles o não reconhecimento e identificação com sua negritude por parte de meninos e meninas negras, o que podemos também indicar enquanto um resultado da ausência significativa de negros na academia seja como docentes quanto como discentes.

Um ano após a implementação das ações afirmativas, em 2005, somente 5,5\% dos jovens pretos e pardos e em idade universitária estavam frequentando o ensino superior. Dez anos após a execução destas estratégias, 2015, 12,8\% dos negros de faixa etária entre 18 e 24 anos conseguiram acessar os cursos de nível superior7. Em 2016, conforme informações divulgadas pelo Instituto Brasileiro de Geografia e Estatísticas (IBGE), o percentual de negros no nível superior, no período de 2005 a 2015, aumentou para o dobro, porém sendo ainda inferior ao número de brancos.

Em 2018, de acordo com os dados divulgados pela pesquisa "Desigualdades Sociais por Cor ou Raça no Brasil" (IBGE, 2019), pela primeira vez o número de estudantes pretos e pardos passou a corresponder a 50,3\%, ou seja, ultrapassando o número de estudantes brancos. Contudo, continuam sendo sub-representados, considerando que são $55,8 \%$ da população do país ${ }^{8}$.

Entretanto, sempre se fazem necessárias reflexões que nos permitam compreender a maneira como vem sendo realizada a inclusão de jovens negros e negras, das periferias,

\footnotetext{
${ }^{7}$ Dados disponíveis em matéria publicada, em 2/12/ 2016, no jornal eletrônico Agência Brasil, de autoria de Isabela Vieira.

${ }^{8}$ Mais informacoes em < https://brasil.elpais.com/brasil/2019/11/13/politica/1573643039 261472.html>.
} 
dos quilombos rurais e urbanos no nível superior e na educação básica, diante de currículos, projetos pedagógicos e docentes que ainda pautam-se em vieses academicistas que negam a existência das diferentes identidades étnico-raciais, de outros tipos de saberes, de outras narrativas e histórias. Então como as universidades vêm incluindo pessoas negras?

Silvio Almeida (2018, p. 27) ao tratar sobre o racismo e suas diferentes modalidades nos apresenta o racismo individual, o racismo institucional e o racismo estrutural. $\mathrm{O}$ primeiro diz respeito ao racismo praticado por indivíduos racistas, seja individualmente ou em grupo. O segundo se refere às ações do Estado que por meio de suas instituições e políticas acabam por reforçar a discriminação e o preconceito racial. O racismo estrutural se trata das fortes articulações do racismo com o quadro da desigualdade social deste país, em que ao tomarmos este por um viés econômico observamos que a maioria pobre e miserável deste país é composta por pessoas negras.

Não há como desconsiderar que este mesmo racismo que é de ordem estrutural se manifesta não somente na não presença de sujeitos negros (sejam como discentes quanto como docentes) mas também no racismo epistêmico, em que negros e indígenas são desconsiderados enquanto sujeitos que produzem conhecimento científico.

A Lei 10.639/o3 surgiu como demanda do movimento negro enquanto estratégia a ser incluída na formulação de Políticas Afirmativas destinadas a intervir no sistema educacional brasileiro fortemente influenciado, desde o Brasil Império, por um modelo europeu, que tradicionalmente tratava a história do país como um desdobramento da história europeia, sempre partindo de referenciais eurocêntricos, não superando representações de subalternidade que sempre tratam o negro como escravo.

Com a mencionada lei passa é ser exigido à inclusão de conteúdos sobre a cultura afro-brasileira e a história da África, modificando a Lei 9.394 de 20 de dezembro de 1996, que instituiu as diretrizes e bases da educação nacional, que após cinco anos foi 
novamente complementada pela Lei 11.645/2008, exigindo-se, assim, nos currículos o ensino da história e cultura afro-brasileira e indígena9.

Contudo, ainda vemos estas leis sendo exigida somente dos cursos de licenciatura, quando na verdade deve se fazer presente em todas as áreas, incluindo os cursos de bacharelado que vão formar profissionais que irão atuar na saúde, na economia, na administração pública, na área sociojurídica e outras. Porém, diante deste panorama, cabe o reforço da Lei $\mathrm{n}^{0} 12.288$ de 20 de julho de 2010, que promulgou o Estatuto da Igualdade Racial, que visa "garantir à população negra a efetivação da igualdade de oportunidades, a defesa dos direitos étnicos individuais, coletivos e difusos e o combate à discriminação e às demais formas de intolerância étnica" (Art. $1^{0}$ - Lei $\mathrm{n}^{0}$. 12.288/2010). Lei esta que passou a afirmar e reafirmar as demandas da população negra na agenda política do país. Para isto é crucial fortalecer, fomentar e cultivar uma identidade racial negra em diferentes frentes de atuação política.

\section{1 - A AUTODECLARAÇÃO E OS SEUS IMPACTOS PARA A EFETIVAÇÃO DE POLÍTICAS AFIRMATIVAS NA AMAZÔNIA PARAENSE}

A Pesquisa Nacional por Amostra de Domicílios (PNAD Contínua 2018) do IBGE divulgou que a proporção de brasileiros que se declaram pretos cresceu em todas as regiões do país no período de 2015 a 2018. Contudo, as regiões com maior avanço foram às regiões do Centro-Oeste e o Nordeste. No Centro-Oeste, em 2015 correspondia a 6,4\% e em 2018 passou para 9,2\%. Enquanto que no Nordeste, possui a indicação de maior proporção de pretos no país (excluindo-se os pardos) foi de 9,2\% para 11,3\%.

\footnotetext{
${ }^{9}$ Apesar da centralidade do presente artigo ser a questão do negro e a sua invisibilidade na Amazônia, assim como a negação de violências praticadas contra pessoas negras, observa-se que mesmo a região amazônica sendo lugar que possui uma identidade regional ligada à figura do indígena, possui uma população que ainda não consegue se ver da mesma forma. Não se lê e não se compreende nem como negra e nem como indígena, ainda recorrendo a uma imagem genérica do que seria o "índio", uma figura unitária, homogênea e mitológica.
} 
No Sudeste há uma porcentagem de $9,9 \%$ e no Sul corresponde a 4,8\%. Quanto à realidade da região Norte o número de pessoas que se declaram pretas é de 7,1\%, número menor quando comparado aos que se declaram brancos $(19,30 \%)$ e pardos $(71,80 \%)$. Resultado: predominância de brancos na região Sul (73,9\%) e Sudeste $(50,7 \%)$ e de pardos na região Norte.

É fundamental trazermos tais dados para a realidade amazônica, sobretudo, quando se problematiza a equivocada compreensão de que não houve uma verdadeira inserção de negros africanos na região amazônica. Na região amazônica, assim como indígenas foram escravizados, os africanos também foram a principal mão de obra explorada, havendo aqui também os desdobramentos da estigmatização histórica do negro.

Em pesquisa realizada pelo IBGE, em parceria com a Secretaria de Políticas de Promoção e Igualdade Racial, em 2010, 76,7\% dos paraenses se autodeclararam pretos ou pardos, sendo que deste total $69,5 \%$ se declaram pardos, enquanto $7,2 \%$ como negros. Tendo sido o estado com o maior percentual de pessoas que se autodeclararam não brancas. Entretanto, tais dados não significa que possuímos uma população que cultive e valorize suas identidades e culturas ligadas a uma história não branca.

Como muito bem problematizado por Peixoto e Silva (2016; p. 565): "mas entre os que se declaram pardos, classificados todos pelo IBGE como negros, não haveria também indígenas, incursos em uma desatenta assimilação oficial?”. Diante desse questionamento evidenciam-se as complexidades em tratarmos sobre a diversidade étnico-racial em uma região que concentra uma população não branca que ainda precisa se descobrir enquanto negra ou indígena. Logo, é fundamental o incentivo às pesquisas e projetos de extensão que visem dar visibilidade a este tema na região amazônica.

Antes de apresentarmos os resultados, é necessário termos compreensão de três importantes categorias para o debate étnico-racial, que são "cor", "raça" e "etnia”, que de modo equivocado são tratados como sinônimos quando não se dá ênfase a um e se desconsidera ou invalida o outro sem haver uma verdadeira imersão em seus significados e sentidos. 
Primeiramente, “cor” se refere aos aspectos fenotípicos, ao que vemos num primeiro momento quanto ao tom de pele e características físicas de alguém. Entretanto, "Cor e traços fenotípicos não podem ser usados como marcadores genéticos de raça, ou seja, o genótipo não corresponde a um único fenótipo” (MIRANDA, 2010, p. 5).

Cor e outros traços físicos não correspondem a genótipos específicos que configurem nos indivíduos o pertencimento a uma raça específica ou diferente. $\mathrm{O}$ termo e a noção de raça se fortaleceram com o advento dos discursos científicos pautados em teorias eugênicas, assentando-se especialmente no branqueamento populacional, promovido no século XIX. As suas bases passaram a ser questionadas a partir dos graves resultados da tragédia nazista, em que pesquisadores passaram a rejeitar a conceituação de raça, invalidando o seu sentido biológico, passando a adotar a palavra etnia para se referir a judeus, ciganos, indígenas, negros e outros (CFESS, 2016; p. 9).

Gomes (2005, p. 45) destaca que a nova postura adotada, a de se descartar o termo "raça”, tinha como intenção salientar e esclarecer que grupos humanos não são marcados por aspectos biológicos, que estariam relacionados aos genitores e ancestrais, mais aos processos sociais, culturais e históricos.

Biologicamente não existem raças humanas diferentes, contudo historicamente o termo "raça" enquanto uma categoria mental da modernidade (QUIJANO, 2005) passou por estabelecer hierarquizações entre os sujeitos que destoavam do padrão branco europeu, passando a estabelecer políticas de condutas racialistas. Kabengele Munanga (2004, p. 9) nos diz:

Insisto sobre o fato de que o racismo nasce quando faz-se intervir caracteres biológicos como justificativa de tal ou tal comportamento. É justamente, o estabelecimento da relação intrínseca entre caracteres biológicos e qualidades morais, psicológicas, intelectuais e culturais que desemboca na hierarquização das chamadas raças em superiores e inferiores.

Portanto, a palavra "raça" carrega importantes significados históricos e ideológicos que vão para além do caráter biológico. É fundamental compreender que as palavras e os discursos representam verdadeiras arenas de disputas políticas e ideológicas, 
que irão revelar processos não somente de controle, mas também de resistência. Os intelectuais negros sabem que só existe uma raça, que é a raça humana, porém em um posicionamento de resistência se apropriam de uma categoria que historicamente foi utilizada como justificativa para inferiorizar, subalternizar e explorar o negro, logo não se utiliza de tal termo numa perspectiva biológica. Da mesma forma que não se limita a uma percepção biológica quando irá se tratar sobre o que é ser negro.

Para Marçal (2011, p. 31) a noção/conceito de raça, assim como a estruturação da desigualdade entre negros e brancos na sociedade brasileira é uma construção social. Infelizmente, nascer negro, apresentar a negritude em pele e cabelos, nesta sociedade que vivemos, não pressupõe que seremos negros orgulhosos, conhecedores de nossas potencialidades enquanto um povo que lutou e sobreviveu há anos de violações, ou seja, ostentar a identidade racial negra. Justamente pelo longo processo e ainda atual de negação e estigmatização do que significaria ser negro. Se assumir e compreender enquanto negro pressupõe um posicionamento de resistência. Como é muito bem afirmado por Oliveira (2004, p. 57) que diz: "ser negro, é, essencialmente, um posicionamento político, onde se assume a identidade racial negra".

Diante das indicações destas importantes categorias, é possível verificarmos um longo rastro de complexidade que envolve o debate étnico-racial, em que muitos ainda se perdem e passam a ter inclusive insegurança para poder se referir ou realizar ações numa perspectiva antirracista. Outro aspecto que deve ser destacado é que raça e negro são categoriais que transbordam posicionamentos políticos e ideológicos, porém poucos o conhecem. Resultado: indivíduos que "enxergam" a sua cor como parda e suas variações (moreno, mulato, cor de jambo, amendoado e outros) não se reconhecem como negros.

É importante ressaltar que "cor" é uma importante categoria para análise das relações raciais que são estabelecidas no Brasil, tornando-se indispensável para que possamos garantir a efetivação de políticas afirmativas (CFESS, 2016, p. 10). Para o IBGE as indicações de cor como "preto" e "pardo" correspondem aos indivíduos negros. Miranda (2010, p. 126) se refere a esta estratégia como "classificação étnico-racial" que se 
constituiria em eixo prioritário para a tomada de organização de medidas para a equidade racial no país.

Compreender sobre a importância da indicação do fator "cor" em qualquer processo de levantamento e planejamento de ações voltadas para a inclusão social deve vir acompanhado sobre o entendimento de que esta definição é extremamente complexa. Miranda $(2010,52)$ salienta que a classificação racial no Brasil além de extremamente complexa é fluida e ambígua.

Kabengele Munanga (2004, p. 52), indica que no Brasil a tarefa de definir quem é negro é difícil, haja vista que ainda sofremos os impactos de um país que além de desenvolvido e civilizado, queria ser branco. Por consequência temos uma população negra que introjetou os ideais do branqueamento, e que ao longo de suas vidas procuram estratégias para se tornarem cada vez mais próximas do branco e um pouco mais afastadas do negro.

Também ressalta que o Brasil difere dos Estados Unidos da América (EUA), onde não existem definições como pardo, mulato ou mestiço (e outras variações), em que qualquer indivíduo que tenha em sua árvore genealógica pessoas negras pode se apresentar como negro independente da sua aparência predominar características brancas. Para o antropólogo africano "Os conceitos de negro e de branco têm um fundamento etno-semântico, político e ideológico, mas não um conteúdo biológico" (MUNANGA, 2004; p. 52), logo, tratando-se de um posicionamento político.

No Brasil devemos também nos atentar a fatores como o Colorismo, que sendo fruto da miscigenação e da ideologia eugenista, promoveu diferentes formas e níveis de manifestação do racismo, que será reconhecida ou não por sua vítima. De Souza Benedito (2018, p. 66) esclarece que academicamente o que se define por Colorismo é a compreensão de que pessoas que possuem tonalidades de pele diferentes da cor negra (escura/retinta) gozem de "privilégios sociais". Reconhecer tal aspecto não desconsidera ou exclui que pessoas pardas não sejam vítimas do racismo, porém devemos dá visibilidade ao fato de que vivemos num país que irá medir a sua forma de tratamento conforme a tonalidade de pele de suas vítimas. 
No Brasil, por consequência na Amazônia, questões sobre raça e etnia ainda estão muito ligadas aos aspectos fenotípicos, no qual os sujeitos ainda não se percebem inclusos e compartilhando da cultura, das histórias e memórias de grupos étnico-raciais específicos. Contudo, isto não impede que estes sintam as formas mais cruéis da discriminação e preconceito racial, tais como, serem perseguidos pela polícia e não ser selecionado para uma vaga de emprego após entrevista, por exemplo.

\section{IV - SER NEGRO NO MARAJÓ: as considerações dos discentes dos cursos de nível superior do município de Breves (PA)}

Breves faz parte dos 16 municípios do Arquipélago do Marajóno, especificamente o Marajó Ocidental, também conhecido como o Marajó das Florestas e possui uma população estimada em 102.701 pessoas, segundo os dados do IBGE, de 2019. Conforme dados reunidos pelo Observatório do Marajó/Lute sem fronteira (2020, p. 71), do total populacional do referido município, $51 \%$ são do gênero masculino e $49 \%$ feminino. Quanto à autodeclaração, $19 \%$ se leem como pessoas brancas e 80\% como negras (a soma de indivíduos pretos e pardos).

Não havendo especificações quanto a esta classificação no município de Breves, mas ao recorremos aos dados gerais do Marajó Ocidental identificamos que 82\% são negros, $17 \%$ branco, $0,68 \%$ se indicam como amarelos e $0,1 \%$ como indígenas. Todavia, salientamos que aspectos como autodeclaração e identidade étnico-racial no território marajoara ainda são verdadeiros desafios para a comunidade local que ainda desconhece a sua história, seus antepassados e sua árvore genealógica, sendo possível observarmos a

${ }^{10}$ O Arquipélago do Marajó está dividido em duas regiões de integração que são: Marajó Oriental e Marajó Ocidental. No primeiro estão os municípios de Cachoeira do Arari, Muaná, Ponta de Pedras, Salvaterra, Santa Cruz do Arari e Soure e no segundo estão Afuá, Anajás, Bagre, Breves, Chaves, Curralinho, Gurupá, Melgaço, Portel e São Sebastião da Boa Vista. Dos 16 municípios, 14 estão nas piores colocações do ranking do Índice de Desenvolvimento Humano (IDH), excetuando-se os municípios de Soure e Salvaterra. Mais informações estão disponíveis no documento "Cadernos do Marajó - Edição Especial 40 dias de Marajó com Coronavírus", publicado no mês de maio deste ano e pode ser acessado no seguinte endereço eletrônico: $<$ www.observatoriodomarajo.org $>$. 
predominância de equívocos em momentos de atividades de pesquisa de campo e de ações formativas.

No município de Breves (Marajó/PA) localiza-se um dos Campis Universitário do Marajó da Universidade Federal do Pará, que oferta o curso de Serviço Social e executa as ações do projeto de extensão Ser Negro no Marajó iniciado em 2017, fruto justamente destas observações. No período de 16 a 20 de outubro de 2017, foi realizado o evento "I Semana Ser Negro no Marajó", que teve como objetivo refletir sobre a história e cultura afro-brasileira, e as condições sociais, econômicas e políticas que são dadas aos sujeitos negros do país e da região da Amazônia marajoara, dialogando sobre a invisibilidade do negro na nossa região.

$\mathrm{Na}$ intenção de compreender as demandas postas pelo município, durante os meses de agosto e setembro realizamos entrevistas com um total de 34 (trinta e quatro) sujeitos, sendo 32 (trinta e dois) discentes de cursos de licenciatura e bacharelado e dois técnicos de instituições de nível superior, uma pública e outra privada. As perguntas visavam contemplar o entendimento que estes tinham sobre a sua raça/cor/etnia e sobre o entendimento de racismo, se já sofreram ou se já praticaram. Essas perguntas foram realizadas com o principal objetivo de compreender se há possíveis lacunas e quais são as que se apresentam enquanto desafios para a garantia de uma universidade que contemple a diversidade.

Nesta pesquisa exploratória verificamos que dos 34 entrevistados, nove se autodeclaram como pretos, 19 como pardos, cinco como brancos, um como amarelo e zero como indígena. A opção "amarelo" foi acrescentada por um dos entrevistados, que não se compreende como preto/pardo, nem branco e nem indígena. Sendo importante salientar que ao longo do diálogo este revelou que percebia o seu "tom" pele como "amarelado" e não era de origem e descendência de países do Extremo Oriente"1.

Outro dado que cabe ser destacado é que os que se autodeclararam pardos não se reconhecem como negros, sendo também, em sua maioria não se percebem enquanto

\footnotetext{
${ }^{11}$ Japão, Coreia e China.
} 
vítimas do racismo. Dos que se autodeclararam brancos, um afirmou que já sofreu racismo. Dos que se autodeclararam pardos somente nove indicaram ter sido vítimas de racismo. Enquanto que os nove que se reconhecem como pretos externalizam experiências com o preconceito racial, destacando-se casos de racismo durante a infância e a adolescência, no qual destacamos os seguintes relatos:

Sim, na rua e até na sala de aula. (K. I. A, Pedagogia, preta; grifo nosso).

Já sim, lembro agora, uma vez quando era criança por uma colega de escola. E até hoje quando algumas pessoas me julgam e eu percebo que é pela minha cor. (P. E. S, Licenciatura em Letras, preta).

E muito! Em balneários, escolas, faculdade[...]. No meio social mesmo. Rua. (J. A. G, História, preta).

Acho que já. Geralmente na infância, na escola, na casa... E muitas vezes por você ter um peso a mais as pessoas acabam cometendo racismo, por isso o preconceito. (S. E.R., Geografia, preta).

Já. Na escola meus colegas me davam apelidos e me excluíam das atividades e que tinha uma colega que dizia não gostar de negro e que eu não era igual a ela. (E. I, preto).

Eu não [cometi racismo], mas já sofri [...] sempre tem aquela coisa de ser "negrinho" ser submisso. Ter um trabalhinho e se contentar com aquilo [...] na escola que sempre tem aquelas brincadeiras até mesmo no âmbito familiar. (S. E, Serviço Social, preta).

Acho que sim [....] acho que foi com a minha ex-sogra com um comentário quando disse que não teria mais os netinhos brancos [...] acho que essa foi a que mais doeu. (S.E.R, Serviço Social, preta).

Dos relatos apresentados, é possível observar que os sujeitos que se autodeclaram como negros acumulam um processo de experiências que se desdobram desde a infância, vivenciando o racismo já na escola, correspondendo às primeiras respostas. O espaço escolar é o primeiro espaço (depois da família) em que temos a nossa primeira socialização, sendo lugar de manifestação e constatação de nossas diferenças perante o outro, porém é uma diferença que não é respeitada.

A escola vem se apresentando enquanto um lugar cruel para a maioria das crianças negras. Considerando que a maioria dos entrevistados é composta por pessoas jovens com idades entre 18 e 29 anos de idade, identifica-se que as suas infâncias e adolescências foram invadidas por ações discriminatórias e preconceituosas, mesmo 
havendo a existência de dispositivos que obrigam professores e gestores estabelecerem ações educativas de combate ao racismo desde 2003.

Ressaltamos que a Lei 10.639/o3 que incluiria nos currículos escolares a história da África e a cultura afro-brasileira, numa abordagem que se desse para além do mês da Consciência Negra e que superasse a apresentação do negro enquanto "escravo" ${ }^{12}$, não foi concretizado e atualmente vem sendo ameaçada diante de um governo que nega as desigualdades raciais deste país.

Quanto às duas últimas falas revelam a experiência com o preconceito racial se espraiando pela vida familiar e afetiva, a partir de comentários jocosos que em forma de "brincadeiras" e cobranças sobre maternidade voltada para mulheres negras revelam o ideal de branqueamento ainda presente em nossa sociedade e cultura. Mesmo aos que se autodeclaram branco e pardo, revela-se, a compreensão de que ser negro no Marajó significa passar por dificuldades por conta da cor da pele, como é possível observar nas seguintes falas:

A maioria das pessoas possui a ideia de que um bandido ou uma pessoa que não possui boas condições financeiras tem a pele escura (negra). Então, no Marajó, além de muitas vezes o negro sofrer racismo apenas pelo seu tom de pele, ainda é muitas vezes acusados injustamente de "bandido", "pobre", etc. (N.O, Não informou o curso, branco).

A única mais próxima é a Maria ${ }^{13}$, mas meus outros amigos negros não me falaram se sofreram racismo, não tenho muito noção. Mas acho que devem sofrer dificuldades. (S.A, Serviço Social, branco).

Ser negro aqui é sofrer vários tipos de preconceito e falta de oportunidades. (D.F, Pedagogia, parda)

Para o negro marajoara o reconhecimento de sua identidade tem sido um dos principais fatores que acabam por não dar visibilidade às ações racistas seja de caráter individual quanto institucional, não havendo a indicação de dados sobre o perfil da sua população carcerária, mulheres vítimas de violência obstétrica, bem como o perfil dos

\footnotetext{
${ }^{12}$ Quando na verdade foi um sujeito, um ser humano, escravizado.

${ }^{13}$ A entrevistada indica as pessoas negras de seu círculo de amizade, para preservar a identidade dela e de sua amiga, colocamos este nome fictício.
} 
desempregados na região marajoara. Encontramos considerações que vão ao sentido desta compreensão na seguinte fala:

Ser negro é [...] a população negra aqui no Marajó é bem grande, só que a gente percebe que as pessoas não se percebem. É por isso que temos movimentos para pensar a questão do negro. É muito forte o racismo e o preconceito contra o negro. A maioria dos meus familiares são negros, só que não se reconhecem. [...] A minha mãe disse que a avó dela não deixou ela casar com um rapaz porque ele tinha 'cabelo duro', sendo que a vovó tem cabelo de negro. O próprio negro não se reconhece. Há poucos debates sobre essa questão no Marajó [...] Tem sim o preconceito e o racismo aqui. (L. I, bacharel em Serviço Social, branco).

Contudo, observamos que a entrevistada acima problematiza sobre a crueldade quanto à ausência de identidade negra e de um orgulho por ser negro, porém está não se inclui, mesmo observando e compreendendo que na sua família há pessoas negras. Este indicativo deve nos mover no sentido de refletir e problematizar sobre os impactos do Colorismo numa região fortemente miscigenada, pois faz com que pessoas mesmo sendo pertencentes a famílias negras não se compreendam enquanto tal em decorrência do tom de pele claro, ou seja, não retinto ou quando possui o tom de pele negro, mas não tem cabelos crespos.

Diante desta afirmação também nos voltamos para o fato de que dos entrevistados, 19 (dezenove) que se autodeclararam pardos, somente nove indicaram terem sido vítimas de racismo. Destas indicações é possível auferir duas possibilidades: 1) de que pessoas pardas (mais próximas da estética construída pela branquitude) no Marajó não são atingidas pelo racismo em suas diferentes modalidades e 2) de que o pardo marajoara não consegue perceber as minúcias do racismo no seu cotidiano.

No presente estudo indicamos a segunda situação, haja vista que no território marajoara ainda se faz necessário o fortalecimento de estratégias pedagógicas que debatam sobre identidade e diversidade étnico-racial, à medida que tanto para alunos, quanto professores e comunidade (em geral) ainda não consegue compreender ofensas, disfarçadas de "brincadeiras" e piadas, quanto à tonalidade da pele ou estrutura capilar de alguém que guarda fortes indícios de uma longa história de subalternização e 
inferiorização de determinados grupos sociais e raciais. Outro importante e agravante resultado é que muitos dos que se declaram pardos não se compreendem enquanto negros. Perante este contexto destacamos, as seguintes falas:

Ser negro no Marajó, para mim, apesar de ser uma região na qual há uma miscigenação muito grande, também é ter luta diária. Pois as pessoas, apesar de terem descendência de negros e índios, acabam se considerando brancas pela cor clara da pele, e muitos são preconceituosos e nos julgam como inferiores. Ser mulher então é bem mais complicado, já que tu tens que mostrar que tu és capaz mesmo sendo mulher e negra. Enfim, ser negro no Marajó, para mim, é lutar contra o preconceito racial e mostrar que a origem é muito rica e que merece lugar nessa sociedade. (P.E.S, licenciada em Letras, preta)

[...] eu não sei se tem algo mais particular [...] mas ser negro aqui parece que é ter que se esconder. Demonstrar os seus traços você acaba sendo muito reprimido [...] As religiões africanas, a pessoa tem que se esconder [...] É um desafio de certa forma porque tem muitas pessoas com a falta de aceitação $e$ não se aceita e identifica como negro. Mesmo sendo da família [...] o desafio vem daí, pois se não se identifica com negro não tem como lutar por mais conquistas. (S.E, Serviço Social UFPA, negra).

A apresentação destes dados nos permite compreender o quanto ainda se faz necessário problematizar o debate sobre a questão étnico-racial na região do Marajó, no município de Breves, tomando não somente na educação básica, mas também a educação de nível superior, no qual também verificamos dificuldades por parte dos discentes em compreender o que são políticas afirmativas, quando possuem inseguranças em como devem se autodeclarar.

\section{CONSIDERAÇÕES FINAIS}

Ao longo de pesquisas de campo que realizamos em municípios como Breves, Melgaço e Portel, com famílias e sujeitos que vivem em situação de extrema vulnerabilidade social são comuns falas que indicam incertezas quanto à identidade étnico-racial, por parte de pessoas que possuem o tom de pele negro retinto e os cabelos lisos, no qual fazem a seguinte demarcação: “não sou preto [...] mas também não sou 
branco", após considerável momento de análise do próprio corpo. A medida que também não cogitam a possibilidade de serem indígenas, então completam : "coloca aí moreno".

Historicamente, conformou-se na Amazônia uma noção de morenidade que nega não somente o negro, mas também o indígena, apesar deste território ainda ser compreendido no imaginário nacional e internacional como "terra de índio", tratando de modo superficial as nossas raízes indígenas, e consequentemente gera a invisibilidade da Amazônia negra, por consequência ignorando a diversidade étnico-racial do amazônida.

Em nossas atividades extensionistas com a juventude negra das periferias dos municípios marajoaras eram comuns, também, relatos de jovens ${ }^{14}$ que mesmo não se compreendendo como negros, exporem (após muito refletir) situações de racismo, tais como o momento de sua primeira entrevista de emprego a não contratação ser justificada com o argumento de que naquele momento eles estariam em busca de "moças brancas" para atenderem ao seu público consumidor, apesar de possuírem um bom currículo.

Quando as crianças negras moradoras da periferia, que num constante ir e vir nos centros das cidades marajoaras, ficam nas ruas pedindo dinheiro para comprar alimento, mas que também nos relatam que a mãe está guardando dinheiro para comprar produtos químicos para alisar os seus cabelos crespos tão prematuramente, pois é constantemente agredida por seus colegas da igreja e da escola que não aceitam as suas características afrobrasileiras.

Todas estas situações nos permitiram idealizar o projeto de extensão (que entra na sua terceira versão) que visa dialogar com a comunidade interna e externa da universidade sobre identidade racial e racismo, a partir de oficinas, rodas de conversas e programações culturais, sendo importantes momentos em que se apresentam novas demandas. Além de procurar registrar os casos de racismo e fortalecer a juventude negra e periférica junto a Defensoria Pública e o Ministério Público.

Enquanto importante resultado destas ações extensionistas e de pesquisa, tivemos a criação do Coletivo de Pretos e Pretas do Arquipélago do Marajó (CPPAM) e

\footnotetext{
${ }^{14}$ Que não foi possível ser tratado no presente texto por conta das restrições comumente dada a um artigo.
} 
futuramente a produção de um documentário que tratará sobre a história e as vivências do negro do Marajó Ocidental, se constituindo em necessário registro de memórias e lutas que serão distribuídas nas escolas públicas dos municípios e assim contribuindo no processo de fortalecimento de uma educação inclusiva e antirracista.

Esta pesquisa também tem como horizonte dar visibilidade às nossas posições enquanto docentes e pesquisadores negros da Amazônia enquanto importantes agentes na promoção de estratégias para combater o racismo. E este caminho deve ser interdisciplinar e transversal, estando presente não somente na extensão, mas consubstanciado com a pesquisa e o ensino, se fazendo emergencial revermos os Projetos Pedagógicos de Cursos não somente das licenciaturas.

Neste trabalho não tivemos como intenção esgotar o debate ou confiar que todos os aspectos tratados tenham dado conta da complexidade exposta nas falas dos nossos entrevistados, assim como nas reflexões sobre uma identidade negra amazônida e marajoara, pois ainda existem fragilidades que necessitam ser refletidas quanto ao debate étnico-racial. A primeira intenção é potencializar e oferecer bases para a efetivação das políticas afirmativas na Amazônia marajoara, especialmente ao Marajó Ocidental, que ainda precisa se encontrar com os seus quilombos e os seus ancestrais africanos.

Aliado a esta intenção, têm-se também o objetivo de dar visibilidade aos casos de racismo que são suavizados e silenciados na vida do negro marajoara, que por não identificar a violência não consegue reagir, seja na sua "sutileza" quanto na sua agressividade. Enquanto o "preto", o "pardo" ou o "mestiço" e o "moreno" têm dúvidas quanto a sua negritude, o Estado, por meio de seus braços e mãos opressoras e violentas identifica perfeitamente quem é negro ou não. Assim, materializando o racismo estrutural por meio de uma necropolítica quem vem dizimando vidas de jovens nas periferias das cidades brasileiras, alcançando inclusive cidades pequenas como as existentes no Marajó.

Ser negro na Amazônia e no Marajó significa diversidade, ou seja, a negritude amazônida e marajoara não é homogênea. Se nos reportamos à pluralidade quando nos referimos às infâncias e juventudes, então também se faz necessários nos referimos à Amazônias, Marajós e negritudes. 
A luta e mobilização também devem ser de caráter epistêmico, no momento, em que consigamos articular de modo integrado e interdisciplinar uma educação de caráter antirracista. No entanto, este movimento não é simples, pois envolve o enfrentamento de toda uma herança que reforçou historicamente o branco, europeu, como sujeito ideal. Cabe à academia enquanto espaço do conhecimento crítico, democrático e inclusivo fomentar processos educativos dentro e fora de seus muros, fortalecendo políticas afirmativas que não chegaram a se concretizar realmente em regiões como a do Marajó.

\section{Referências}

ABREU, M.; MATTOS, H.; DANTAS, C. V. Em torno do passado escravista: as ações afirmativas e os historiadores. Antíteses, vol. 3, n. 5, jan.-jun. de 2010, pp. 21-37. Disponível em <http://www.uel.br/revistas/uel/index.php/antiteses>.

ALBUQUERQUE, W. R. de, FRAGA FILHO, W. Uma história do negro no Brasil /Salvador: Centro de Estudos Afro-Orientais; Brasília: Fundação Cultural Palmares, 2006.

ALMEIDA, S. L. de. O que racismo estrutural? - Belo Horizonte (MG): Letramento, 2018.

AZEVEDO, A. D. M. de; PERES, E de S. A presença negra na Amazônia: um olhar sobre a vila de mangueiras em Salvaterra (PA). Revista Marupiíra, Belém,V. 2, p. 08-15, 2015 .

BEZERRA NETO, J. M. A presença negra no Pará: resenha de um trabalho pioneiro. Revista Estudos Amazônicos - Vol. III, nº 1, 2008.

CFESS/Comissão de Ética e Direitos Humanos CFESS. Assistente Social no combate ao preconceito - racismo.Brasília (DF), 2016.

DE SOUZA BENEDITO, M. A relação entre Psicologia e Racismo: as heranças da clínica psicológica. São Paulo, 2018. 108 f. Dissertação (Mestrado em Psicologia Social), Instituto de Psicologia, Universidade de São Paulo.

GOMES, N. L. Alguns termos e conceitos presentes no debate sobre relações raciais no Brasil: uma breve discussão. In: BRASIL. Educação Anti-racista: caminhos 
abertos pela Lei federal no 10.639/o3. Brasília, MEC, Secretaria de educação continuada e alfabetização e diversidade, 2005. (p. 39 - 62).

MUNANGA, K. A difícil tarefa de definir quem é negro no Brasil. Estudos Avançados 18 (50), 2004.

MARÇAL, J. A. A formação de intelectuais negros(as): políticas de ação afirmativas nas universidades brasileiras. Belo Horizonte: Nandyala, 2012.

MARÇAL, J. A. Política de Ação Afirmativa na Universidade Federal do Paraná e a Formação de Intelectuais negros (as). Curitiba, 2011. 195 f. Dissertação (Mestrado em Educação), Universidade Federal do Paraná.

MIRANDA, M. Classificação de raça, cor e etnia: conceitos, terminologia e métodos utilizados nas ciências da saúde no Brasil, no período de 2000 a 2009. Rio de Janeiro, 2010. 137 f. Dissertação (Mestrado em Saúde Pública) - Escola Nacional de Saúde Pública Sergio Arouca.

OLIVEIRA, F. Ser negro no Brasil: alcances e limites. Estudos Avançados 18 (50), 2004.

PEIXOTO, R. C. D.; SILVA, J. S. da. Segregação racial na orla de Belém: os portos públicos da Estrada Nova e o Ver-o-Peso. Bol. Mus. Para. Emílio Goeldi. Cienc. Hum., Belém, v. 11, n. 3, p. 563-579, set.-dez. 2016.

PRIORE, M. D.; VENÂNCIO, R. Uma Breve História do Brasil. São Paulo: Editora Planeta do Brasil, 2010.

QUIJANO, Anibal. Colonialidade do poder, eurocentrismo e América Latina. En libro: A colonialidade do saber: eurocentrismo e ciências sociais. Perspectivas latinoamericanas. Edgardo Lander (org). Colección Sur Sur, CLACSO, Ciudad Autónoma de Buenos Aires, Argentina. setembro 2005. pp.227-278.

SALLES, V. O negro na formação da sociedade paraense: textos reunidos. 2. ed. Belém: Paka-Tatu, 2015.

SALLES, V. O negro no Pará: sob o regime da escravidão. Rio de Janeiro, Fundação Getúlio Vargas, Serv. de Publicações [e] Universidade Federal do Pará, 1971. 
SARRAF-PACHECO, A. Os Estudos Culturais em outras margens: identidades afroindígenas em "zonas de contato" amazônicas. Fênix - Revista de História e Estudos Culturais, Vol. 9 Ano IX n ${ }^{0}$ 3, 2012.

STEPAN, N. L. A Hora da Eugenia: Raça, Gênero e Nação na América Latina. Rio de Janeiro: Fiocruz, 2005.

\section{Sobre a autora}

Jacqueline Guimarães: Assistente Social, doutora em Educação, Coordenadora do Programa DIDHAM (Direitos Humanos, Infâncias, Diversidade no Arquipélago do Marajó) e Docente da Faculdade de Serviço Social do Campus Universitário do

Marajó/Breves - FACSS/UFPA. E-mail jacquetsg@gmail.com 